\title{
A Watershed Perspective in a Site Specific World 1
}

\author{
by
}

\section{D.J. Wilford ${ }^{2}$}

\begin{tabular}{|c|c|}
\hline Abstract & Résumé \\
\hline $\begin{array}{l}\text { A watershed perspective is essential to good forest } \\
\text { management. The considerations that this entails are } \\
\text { discussed and recommendations made. }\end{array}$ & $\begin{array}{l}\text { Une perspective globale d'un bassin versant } \\
\text { est essentielle pour réaliser un bon aménagement } \\
\text { forestier. Les considérations que comporte cette } \\
\text { perspective sont discutées et des recommandations } \\
\text { sont formulées. }\end{array}$ \\
\hline
\end{tabular}

\section{Introduction}

Foresters in British Columbia have clearly recognized the need to be site specific when harvesting and establishing new stands. This recognition is an essential prerequisite for forest management; however, it has developed into somewhat of a dogma - "If we are site specific, all will be well in a watershed". Evidence suggests that an additional, broader perspective is necessary for the sound management of forest land resources. This paper draws on some of the evidence and proposes that more emphasis be given to the watershed perspective.

\section{Definitions}

The following definitions will be used in this paper:

A site is a unit of land that is sufficiently uniform from an ecological and physical standpoint that a given forestry treatment will produce a reasonably consistent result.

Very few sites function in isolation, that is, they are influenced by upslope or upstream processes. Since water is the primary factor in the interacting process, the best way to define the zone of influence on a site is through a watershed. A watershed can be defined as a landscape unit that is topographically defined by heights of land. The size of watershed will vary from the 1 to 2 hectares of hillslope draining onto a specific site, to the 10000 hectares providing streamflow past an alluvial site.

The most important factor to recognize is that watersheds are a mosaic of sites, integrated by water. Water can be a pure liquid, or it can be in a slurry with soil and debris, as in a debris

\footnotetext{
Paper given at the Hydrology Working Group Meeting at the Annual Meeting of the CIF in Victoria, B.C. September 1986

${ }^{2}$ Research Forest Hydrologist, BC Forest Service, Smithers, B.C.
}

torrent. Since water is such an important link between sites, it is important to know how water, in all of its forms is influenced by a site and modifications to a site. This is the field of site hydrology.

\section{Site Hydrology}

Much hydrology research has been conducted at the site level. It is clear that forest management practices, from harvesting through stand tending, influence site hydrology. Site hydrology factors that are influenced include:

- evapotranspiration

- snow accumulation and melt

- erosion

- routing of soil water

The influences range from positive where forest hygiene is improved, to negative where mass wasting is increased. Whether the influence is positive or negative, the fact that there is change associated with forestry practices should be kept in mind. In addition, the change or impact may be minor on a given site, but may be significant further down a watershed. For example, a small landslide develops on a site, and progresses downslope, cutting a swath through a thinned plantation. Another example is where high-elevation forest sites are logged, leading to earlier snowmelt. If the melt reinforces low-elevation snowmelt, the resulting increased flows may lead to accelerated streambank cutting and loss of productive alluvial sites. Thus, it is necessary to look beyond a single site to recognize both on- and off-site hydrologic influences. This leads to the watershed perspective.

\section{Watershed Hydrology}

Watersheds are a mosaic of sites, linked by water. This is a simple concept, yet one that has major implications for how and why forests are managed. If forests are managed with only a site specific focus, it is possible that both the forest and water based resources will suffer. Several avenues will be explored to illustrate why this is so: erosion, alluvial sites, streamflows, and cumulative effects. 


\section{Erosion}

Erosion is a two way street in forested watersheds. Natural erosion can influence forest sites. Natural levels of erosion can be accelerated by forestry practives.

Natural Erosion. Most forest inventories in British Columbia classify unstable terrain (e.g. the environmentally sensitive areas noted on BC Forest Service inventory maps). At the operational level, many plans include terrain maps that identify in more detail unstable areas and include harvesting/ road building prescriptions. This is site specific work that has great value, but is it enough? Do we need a broader perspective?

Throughout the world, protection forests are managed to maintain the "forest influence". One particular influence is that of maintaining slope stability. Forests are managed with the selection silvicultural system to maintain a thrifty root system - an important component of soil shear strength. The costs of such management are balanced by the downslope values in many cases these are villages and main highways. The type of sites that are identified as protection forests include naturally unstable areas. Since in British Columbia we have identified unstable sites, should they be managed to maintain the forest influence? The answer to this question becomes more apparent every year as we invest more funds in forest plantations below naturally unstable areas. Other land modifications such as highways and logging camps, and fish habitat improvements call for the need to reduce the natural hazard levels.

Foresters have the techniques to maintain the forest influence, but some sites must be managed with a watershed perspective - for the sake of watershed or downslope site values, the net return from a site is not maximized.

Accelerated Erosion. Forestry operations expose mineral soil, modify slope stability, and re-route soil and surface water. All these factors lead to erosion. Years of research has documented accelerated erosion and led to significant advances in erosion control measures. We have gone a long way in British Columbia towards recognizing and reducing erosion, but four factors remain a concern.

First, it is not possible to identify all potential sources of erosion. Unexpected landslides occur. More detailed terrain maps may be a solution, however, we are still opening up new ground, and as with most pioneering work, surprises can occur.

Second, there can be a considerable delay following forest harvesting before erosional problems develop. This can be due to the slow decay of tree roots or the lack of a storm of sufficient magnitude to cause appreciable erosion. Again, this is a problem associated with pioneering, but is compounded by the fact that the logging operator may have left the area, making rehabilitation difficult. Unfortunately, with 'mobile' operators, knowledge is not always gained and applied to another area (we don't always learn from our mistakes). Delayed erosion can also be associated with stand tending such as the removal of alder before the coniferous regeneration has developed an adequate root system to maintain slope stability.

Third, not all logging operators use the current knowledge. Reasons for this include cost, lack of recognition of the erosional problems, and lack of understanding of erosional processes.
Fourth, although erosion may be minor at the site level, the cumulative effect downstream may be important. For example, research done on sedimentation problems in the Olympic National Forest identified road surfaces as the major source of sediment. Most people do not recognize the significance of surface erosion, let alone road surfaces as surface erosion sites, yet this is one of the background sources of fines to streams, and all sources are cumulative.

For these reasons, it is necessary to take a watershed perspective of erosion, and address questions of impacts not only to fish habitat but also to forest sites and roads.

\section{Alluvial Sites}

Several aspects of forest management on alluvial sites require a watershed perspective - treatment timing, site longevity, and the role of these sites in aquatic productivity

Treatment Timing. Many alluvial sites become free of snow early and permit early spring planting. Thought, however, should be given to the probability of flooding later in the season owing to snowmelt and runoff at high elevations. There are two aspects to consider, one at the site and the other at the watershed level. At the site level it is necessary to determine the extent of low-lying ground, and to gain an appreciation of past flooding. Specific signs are fresh alluvial deposits, evidence of water flowing through the area (e.g. driftwood and shifted logs), and soil morphologic features such as mottling and gleying. At the watershed level, it is necessary to gain a feeling for the expected runoff. This entails using information from the Snow Survey Bulletin and streamflow records. Generally this information is not available for a specific watershed, however data from the general area will provide knowledge of regional runoff characteristics and what can be expected in a given year.

Site Longevity. Alluvial sites are generally goemorphically active. That is, they are constantly being affected by the adjacent stream or river (i.e. bank cutting and deposition). Since forestry is a long-term undertaking, it is necessary to be fairly confident that the site will remain intact. To do this it is necessary to go beyond the site and take a watershed perspective to determine how active the river or stream is. This can be quite straightforward in some systems, but may present quite a challenge in others. For example, steepgradient alluvial fans that have been formed where streams enter a main valley can remain stable for long time, but the channel may be slowly aggrading and 'decide' to change course following a costly stand tending treatment. To practice forestry successfully on alluvial sites, site longevity must be determined.

Aquatic Productivity. Many streams in British Columbia rely on inputs of material from streamside vegetation to remain productive. The material is necessary to maintain physical stability (e.g. large organic debris) and food chains (e.g. nutrients in groundwater, litter and terrestrial insects). Timber production on alluvial sites can be compatible with aquatic productivity, but special measures must be taken. In British Columbia we have developed special site specific prescriptions, but do they go far enough to ensure long-term physical and biological productivity. Are we managing streamsides to provide long-term inputs of large organic debris? If the large debris is not replaced, what are the implications for the stability of downstream alluvial sites? 
Given the biological significance of red alder to streams, have foresters considered it seriously enough as a commercial species? We need a watershed perspective .... and the benefits will not be just for the fish resource.

\section{Stream Flows}

Both peak flows and low flows can be influenced by forest management.

Peak Flows. Considerable research has been conducted on the influence of forestry practices on streamflows. Peak streamflows have been found to increase, decrease, and stay the same following clearcut logging. Generally, the major runoff events such as 25-year storms are not affected because the runoff event is so strongly dominated by a weather system. However, the shorter return period events can be increased. Is this a concern? This is a difficult question to answer for several reasons. First, in British Columbia we lack long-term stream inventories and detailed streamflow records that would show whether increases are occurring and whether they are having an influence on channel morphology and gravel quality. Secondly, it is frequently difficult to find a watershed that has had a high level of harvesting and has not received direct stream channel impacts (e.g. a landslide or large input of fine debris). We are left with two things to consider:

- given that streams are altered during periods of high flow, if the frequency of high flows is increased as a result of forest harvesting, would it not follow that channels will change?

- given that stream channels have been affected by logging, is it reasonable to try to isolate and weigh individual factors such as peakflows (process orientation), or should we look at the end result (affected channels) and attempt to correct those things that are apparent factors, and can be conservative with regard to factors that could be involved with the end result?

These questions are a long way from being resolved in British Columbia, and perhaps may never be totally resolved due to the limited data base. We shall have to rely heavily on research done elsewhere. One thing that has become clear to researchers and resource managers in the US Pacific Northwest is that the speed of forest harvesting has been linked to increases in peak flows and channel changes. This recognition has led to recommendations on the rate of harvesting in watersheds that are much lower than we are practising in British Columbia.

Peak flows and channel stability are factors that require a watershed perspective to analyze changes and potential changes.

Low Flows. Research results indicate that forests can be managed to increase low streamflows by creating gaps in the canopy to increase snow accumulation and decrease melt rates. In addition, with the removal of the mature trees, evapotranspiration is reduced, and the net result is increased low streamflows. Only recently has the question been raised - what happens to low flows when harvested areas regenerate and the young trees are actively transpiring? Will flows drop below the preharvest level? Is there reason to be concerned about the extent of immature forests in a watershed (i.e. the rate at which the old growth is harvested)? In watersheds that have high levels of erosion and deposition of gravels in the stream channels, is it possible that increases in evapotranspiration may aggravate existing low flow problems?

The Sequoia forests on the California coast provide an interesting hydrologic example. The rainfall in the area is too low to allow trees to grow, but with the coastal fog and the resulting condensation in the tree canopy, there is adequate moisture for growth. This example helped to solve an anomoly that occurred following logging in one of Portland's domestic watersheds. With logging, low flows were expected to increase due to the reduction of evapotranspirational water losses. However, low flows declined. It was subsequently found that condensation of fog in the mature forest canopy provided a significant amount of moisture for low flows. Does the same process occur in British Columbia? The Portland watershed conclusion was possible due to close observation and streamflow monitoring. Are we monitoring our watersheds closely enough in British Columbia to detect changes that may be critical for spawning salmon? The forests on fog-belt sites are characteristically very valuable for timber production. These sites may also be very important from a watershed standpoint.

\section{Cumulative Effects}

Watersheds are a mosaic of sites, linked by water. As water passes from one site through another, there is an integration of influences. With forestry activities there is a change in the influence that sites exert on water, and thus a change in the overall 'integration' value. The net value can be positive or negative, and it may influence only one or several watershed values. The term 'cumulative effect' has been used to define the net result of forest land-use practices. This is easy to identify if there has been a dramatic impact such as a landslide that has created a new stream channel or cut a broad swath through a plantation. However, it is possible to have subtle changes in individual hydrologic factors, that when acting together produce a significant change in a watershed. The goal of sound watershed management is to manage so that no single resource is significantly affected. This entails ensuring that cumulative impacts do not exceed certain critical levels. Although this is relatively easy to conceptualize, it is a difficult goal to achieve due to the:

- lack of a 'pre-forestry' inventory and data base from which to judge impacts.

- lack of intensive monitoring to detail impacts.

Added to this are the vagaries of nature and the element of time:

- natural climatic, physical, and biological conditions. If conditions are violent, it is difficult to separate natural from forestry-related cumulative effects. If conditions are mild, it is possible to assume no impacts, when in fact they will occur as soon as conditions return to "normal".

- time for impacts to occur. For example, root decay takes from 5 to 15 years to significantly reduce slope stability. Lobes of bedload in a stream may require many years to be transported down to productive fish habitat.

And, since fish don't act in isolation, there is an added problem: - 'outside' watershed pressures such as over harvesting of fish and pollution may be the dominant reason for low productivity in streams (i.e. low recruitment). 
Even in experimental watersheds it is difficult to interpret cumulative effects because - we have an incomplete understanding of what impacts mean in a biological sense both to fish and trees. Added to this is an incomplete understanding of geomorphology and what chain of events occur after something is initiated. In total, we have an incomplete knowledge of a very complex system.

So, where does this leave resource managers? It is recognized that forestry practices have affected both forest sites and streams. This recognition has led to more intensive planning and site specific prescriptions. Has this done enough to reduce impacts to an acceptable level? This must be answered at the watershed level, where cumulative effects become apparent. Science can provide some assistance towards identifying cumulative effects, but the bottom line in British Columbia is technical judgement. Given that many effects require time, developments in a watershed should be conducted at a reasonable pace to allow for monitoring and feedback - two essential components of judgement. The objective should be to exercise judgement before significant cumulative effects occur.

If there is an error in judgement and important cumulative effects occur, the net effect can be long-term impacts to watersheds. Where rehabilitation has been attempted, the general conclusion has been that efforts were expensive, difficult, and not successful. This, while every effort should be made to reduce hydrologic impacts at the site level, cumulative effects should be a basic consideration at the watershed planning level.

\section{Conclusions}

Foresters must be site specific in developing prescriptions and treatments. However, sites should not be viewed in isolation as they form a mosaic, linked by water in a watershed. The hydrologic effect of site treatments can have a cumulative influence that can be negative for both forest sites and stream channels. To practice sound forest and watershed management, foresters require a watershed perspective.

\section{Membership Dues 1987-1988}

\section{National Dues}

\section{Active Membership}

1 st and 2 nd year after graduation

grad 1987, grad 1986)

Other new Active Members 1 st year

All other Active Members

\section{Affiliate Membership}

1 st and 2 nd year after graduation

(grad 1987, grad 1986)

Other new Affiliate Members 1st year

All other Affiliate Members

Members with Retired Status receiving

The Forestry Chronicle

Members with Retired Status not receiving

The Forestry Chronicle

Student Members

Sustaining Members (CIF)

Sustaining Members (Other)
$\$ 67.00$

$\$ 67.00$

$\$ 94.00$

$\$ 67.00$

$\$ 67.00$

$\$ 88.00$

$\$ 29.00$

$\$ 00.00$

$\$ 27.00$

$\$ 30.00$

$\$ 200.00$
Section Dues

NS $\$ 5.00$

OK $\$ 5.00$

OR $\$ 5.00$

OV $\$ 8.00$

PA $\$ 8.00$

RM $\$ 10.00$

SK $\$ 10.00$

$\mathrm{SN} \$ 8.00$

SO $\$ 10.00$

SO (STUDENTS) $\$ 2.00$

VA $\$ 10.00$

VI $\$ 5.00$

Upon written application, spousal members may have the dues of one of them reduced by the amount equivalent to the price of an individual Canadian subscription to The Forestry Chronicle. Spusal members are members of the same Section who are living together as spouses and using the same mailing address.

The Institute year runs from July 1 to June 30 . Applications dated after January 1 will be charged half dues for that Institute year. Applications dated after April 1 will be charged no dues for that Institute year.

Section dues are in addition and range from $\$ 5.00$ to $\$ 18.00$. 